\title{
How Remote Response Devices Enable Student Learning: A Four-Year Analysis
}

William A. Anderson, Georgia Southern University, USA

Thomas G. Noland, University of South Alabama, USA

\begin{abstract}
The use of Personal Response Systems (PRS) / Classroom Performance Systems (CPS) has expanded considerably since introduction in the early 2000s. Much of the exploration of the technology has focused on methodology, student participation, and student perception. This paper examines actual testing results over nine semesters to provide some insights to the impact of the technology on student grades.
\end{abstract}

Keywords: Teaching Methods, Personal Response Systems, Clickers, Classroom Enablers

\section{INTRODUCTION}

$Q$ $\mathrm{n}$ article appearing in the Chicago Tribune (Cohen, 2005) provided the motivation to begin implementation of the Personal Response System (PRS) "clickers" technology. The article focused primarily on the use of remote response units as an immediate means of student feedback; i.e., gaining insight as to whether students grasp the concepts being taught.

Subsequent inquiry at Georgia Southern University's College of Business Administration revealed a prototype program for the implementation of using clickers in the classroom. The PRS approach adopted at Georgia Southern University was the "Classroom Performance System" by eInstruction, hence, the abbreviation "CPS." One of the participants in the program was Dr. Stephen Rutner, who had previous experience with clickers and had written an extensive article on the technology (Rutner, 2004). Rutner's findings were that the overall impact on student learning was about one-half a letter grade improvement. He offered encouragement to take action with the technology and keep records of the results.

After deciding that the use of clickers might be a viable way to improve student performance, an overarching strategic objective was determined:

- Increase student understanding and retention of concepts.

Use of the CPS approach supported several important intermediate objectives:

- $\quad$ Get feedback on student understanding of concepts in advance of actual testing.

- $\quad$ Create a strong impetus for students to read the cases before class.

- Increase the opportunity for student participation in the classroom.

- Increase the number of cases discussed in classroom without creating a workload monster for either the student or the instructor.

\section{PRIOR RESEARCH}

Most of the prior research on the use of remote access devices has focused on student satisfaction and student participation in the classroom. Hatch (2005) utilized clickers in an introductory anatomy and physiology course. Hatch found that $92 \%$ of the students felt that the clickers helped them see what they know or do not know and $83 \%$ felt that clickers were helping them to learn during class time. 
Herreid (2005) found that clickers were ideally suited for case teaching using the Interrupted Case Method. The Interrupted Case method as used by Herreid integrates lecture material, case scenario material, student discussion with their neighbor, clicker questions, clarification of the answers, more lecture and data, then the cycle is repeated. In a general biology class with a class of 450 students, Herreid found that utilizing clickers after each stage of the case increased attendance, engaged students and improved class grades (but he doesn't state by how much grades improved).

Francisco (2006) found students in operations management courses were more favorable to the use of clickers than students in either accounting information systems courses or principles of retailing courses. Operation management students recommended the use of clickers at a higher rate and stated that clickers helped create a better learning environment. The variables that could have contributed to the deviation between classes could include instructor differences, different classroom methodology and differences in class personality.

Carnaghan (2007) found strong student satisfaction with the technology. Carnaghan also found that students felt that the technology improved their performance. However, Carnaghan findings suggest that learning effects are limited when measured by exam performance. Positive exam effects were found only for exam questions that were similar to the in-class questions covered with the remote access devices.

Stowell (2007) compared using clickers against both hand-raising in class and the use of response cards for students enrolled in an introductory psychology class. Stowell found that formal participation was greater with the use of clickers that with either response cards or hand-raising. However, Stowell found no significant differences on post class quiz performance between the three methods. Stowell did find that the actual quiz performance of the clicker group more closely reflected learning as their quiz scores were more aligned with in-class measurements of learning than either the hand-raising or response card measurements.

In a 2008 paper, Cunningham (2008) reported mixed results. Utilizing clickers in two large-lecture sections of introductory accounting courses (about 840 students), he found that about $49 \%$ of students believed that the student response system should continue to be used while $28 \%$ felt that it should be discontinued. The remainder of the class either had no opinion or no response. Only $8 \%$ of students reported that they prepared more for class knowing the response system would be used to test his/her knowledge of the subject. Nearly $73 \%$ reported that they did not prepare more for class. Cunningham did find that over 55\% of students found that the response system added interest to the class. Cunningham found that some of the negative student responses included such items as clickers do not work, the cost to the student, cannot participate when you forget your clicker and some people cheat by allowing friends to bring his/her clicker to class.

Other research such as Barber (2007) compares the different types of clicker systems available and the strengths and weaknesses of each system. Barber does not recommend any system but does state institutions should adopt a single clicker system because it reduces costs for the student and reduces the number of systems the university needs to support. Standardization allows faculty to learn a single system and become more proficient with the technical capabilities of that system.

\section{CLASSROOM RESULTS}

Figure 1 shows that after the implementation of CPS, test scores improved by over one-half letter grade. Prior to utilizing CPS, the class average test grade over a three-semester period (Spring 05-Spring 06) was 71.83. After implementing CPS, the test average for the next three semesters (Fall 06-Fall 07) rose to 75.30. Over the following three semesters (Spring 08-Spring 09), the test grade average rose to 78.27. The overall increase of 6.44 points represents better than a $1 / 2$ grade increase - in this case from a low $\mathrm{C}$ to almost a $\mathrm{B}$ average. These findings aligned with Rutner's previous findings that the use of the CPS improved test scores by about $1 / 2$ letter grade.

The data was accumulated from Introductory Operations Management classes taught by the same instructor over nine semesters. The average number of students per semester was 94 , with a range of 40 to 142 (Figure 2). The number of classes each semester ranged from 1 to 4 with 3 and 4 being most typical. 
It should be noted that CPS was not directly responsible for the results. It was the enabler. It allowed the introduction of a greater number of in-context business articles and cases and provided both feedback about students' understanding and a measurable indication of their classroom participation. Most importantly, CPS provided an inducement for students to read over the material before it was discussed in class. The use of the CPS allowed the instructor to add more cases over time. Prior to utilizing CPS, the instructor was covering four cases per semester, after six semesters of using CPS, the number of cases covered had grown to 15 .

Figure 1

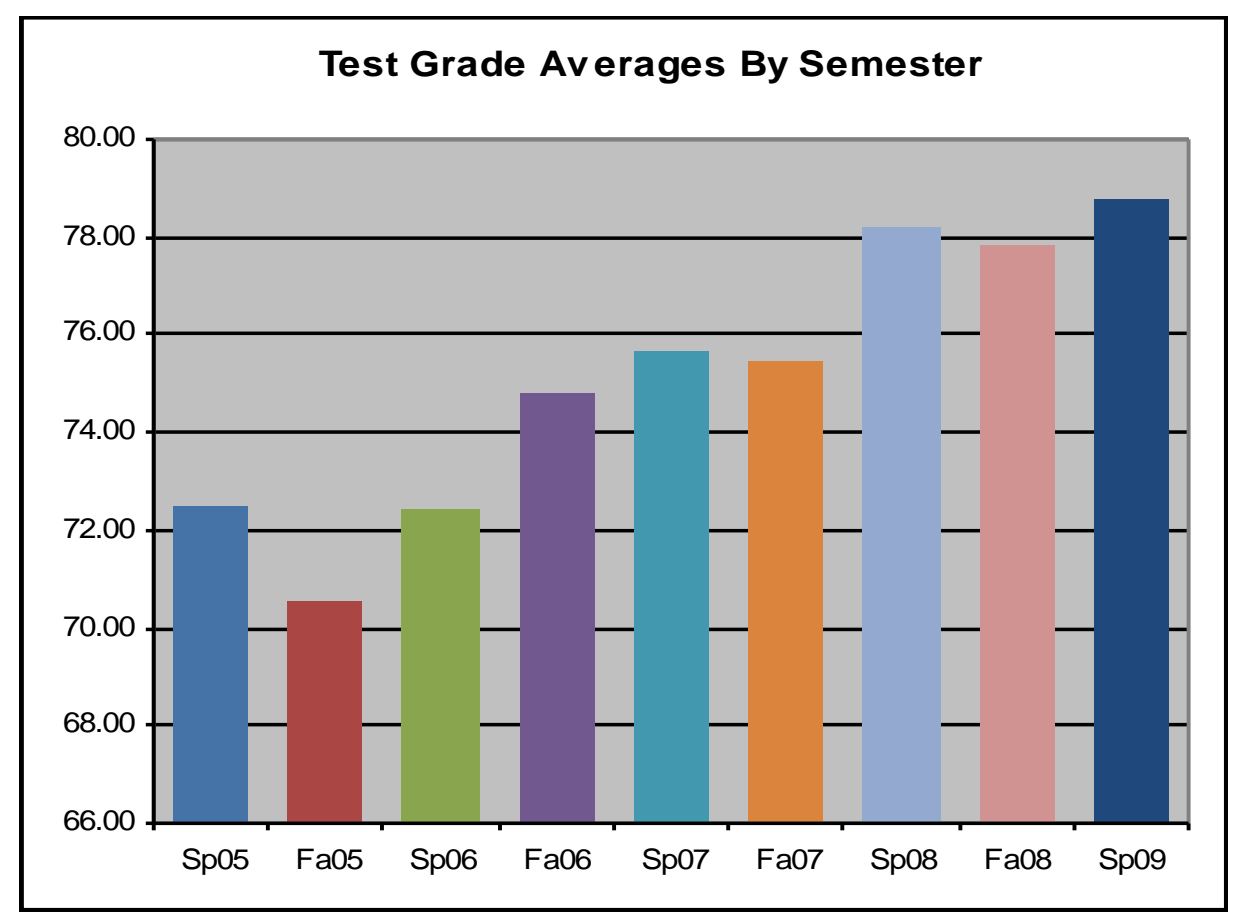

Figure 2: Number of Students and Cases Per Semester

\begin{tabular}{|c|c|c|c|}
\hline Semester & \# of Classes & Total Students & \# of Cases \\
\hline Sp-05 & 4 & 121 & 3 \\
\hline Fa-05 & 2 & 67 & 3 \\
\hline Sp-06 & 4 & 96 & 6 \\
\hline Fa-06 & 4 & 128 & 8 \\
\hline Fp-07-07 & 4 & 142 & 8 \\
\hline Sp-08 & 3 & 72 & 12 \\
\hline Fa-08 & 1 & 40 & 15 \\
\hline Sp-09 & 3 & 101 & 15 \\
\hline
\end{tabular}

\section{Time investment - pre-classroom}

Preparing case questions for classroom use involved reading the case, and then one to two hours to put together suitable questions. Questions for cases were oriented toward three aspects:

1. Have students read the case?

2. Did students understand the concepts involved in the case?

3. Is the student able to relate a concept to another situation? 
In addition, each class must be set-up at the beginning of each semester. This involves logging on to the host site (www.einstruction.com) and creating each class by following a guided script. These steps are pretty routine and require $1 / 2$ to 1 hour of time. One of the outputs is a Student Handout Sheet with the "class key" and instructions to register online to that specific class. A copy of this Student Handout was then provided to each student. The "class key" is different for each class and when the student goes on-line with eInstruction to register, it is the "class key" that links the student and the student's "clicker" to the specific class. It can be expected that one student in about twenty-five will have a problem with registration - usually fairly easy to correct..

\section{Using CPS in the Classroom}

CPS has far more facets and capabilities than were utilized. Pareto's 80/20 rule was applied to take advantage of the $20 \%$ of the system that would provide $80 \%$ of the primary objectives. The $80 / 20$ approach was intended to keep the instructor learning curve relatively short and minimize the time investment to get started.

Using CPS in the classroom is straightforward. (Remember that only $20 \%$ of the CPS capabilities were being utilized.) Arriving at the classroom five minutes prior to the start of each class allowed adequate time to load the CPS Database from a flash-drive and initiate the software. Students merely had to turn on their response units, "clickers", to be logged in for responses.

Each question and multiple choice or true/false answers are projected on the screen (A typical case question used in the CPS can be found in Figure 3.) Students respond using their remote units. After each question is closed i.e. student answers to that question are no longer accepted - the summary of overall responses to the question is shown. The response distribution provides immediate feedback and guides discussion. The CPS software automatically enables this process.

The instructor had found that just assigning cases to be read did not get the cases read by the majority of students. Assigning written analysis meant reading and grading the student submissions, which in turn proved to be time consuming. Assigning more cases, and assuring they were read, required a more efficient approach. CPS offered an effective approach for giving students the impetus to read the cases/articles before class discussion and an easy way to track both the quality and quantity of participation.

It was evident in the classroom that most students were reading the cases prior to class, resulting in better discussion and understanding. The CPS enabled the instructor to receive immediate feedback of the level of understanding and address any shortfalls immediately. This approach is far more interactive than finding out that students are not grasping a concept when they take a test several weeks later. Utilizing the CPS allowed the use of more cases to provide an example of a concept in action. The number of cases and articles used nearly quadrupled after the introduction of CPS.

The CPS approach also makes it easier to connect concepts that are interrelated but presented at different times. For example, in operations management the relationships between types of strategy, appropriate process approach, and related issues about inventory and lean methodology are all normally covered at different times in the semester. By utilizing the CPS to ask case questions, the instructor can test the student's understanding of the interrelationship of these topics.

\section{Figure 3: Typical CPS Question}

Students are assigned a short case to read. Then asked questions relating to the concept topic as well as the case This question happens to be about the use of Operations Management methodology in a barber shop (Heizer and Render, 2006).

Question: In the Barber Shop case, a service, the owner incorporated techniques and approaches that are conceptually similar to which production process type?

A. Product Focus - high volume, low variety

B. Process Focus - low volume, high variety

C. Repetitive Focus - Use of modules (parts \& components previouslv prepared) 
While anecdotal in nature, the instructor observed an increase in the quality of classroom discussion and the number of different students who would actively and intelligently participate in classroom interaction.

\section{CONCLUSION}

Remote response devices such as the CPS have the potential to improve student performance. The use of clickers in the classroom can serve as an enabler for students to improve their knowledge and retention of key concepts. Using CPS enabled test scores to increase by over $1 / 2$ letter grade over a four year period. Utilizing CPS creates an impetus for students to read assigned cases before class and creates an environment that increases both the quantity and quality of classroom participation.

The use of CPS allows more cases/material to be assigned which enhances learning. The instructor was able to nearly quadruple the amount of cases covered in a semester by utilizing CPS. The CPS gives both the instructor and students feedback on the comprehension of concepts prior to actual testing. Instructors are given immediate responses about student comprehension and can either move faster through the material or slow down and cover in more detail those subjects that students find more difficult. The use of CPS will continue to enable student learning as its usage becomes more widespread as technology continues to improve.

\section{AUTHOR INFORMATION}

William A. Anderson is an instructor in the College of Business Administration at Georgia Southern University. $\mathrm{He}$ is a retired corporate executive and consultant. Mr. Anderson retired as a Captain from the United States Naval Reserve where he specialized in Naval Intelligence. Mr. Anderson has an MBA from Northwestern University and studied strategy and planning at the Navy War College and national security at the National Defense University.

Thomas G. Noland is an Associate Professor in the Mitchell College of Business at the University of South Alabama. He previously was an Associate Professor at Georgia Southern University. He holds a Ph.D. from the Patterson School of Accountancy at the University of Mississippi and an MBA from the Georgia Institute of Technology. He holds professional certifications as a Certified Public Accountant, Certified Management Accountant, and Certified Defense Financial Manager. Dr. Noland holds the rank of Lieutenant Colonel in the Army Reserve and is a graduate of the Army Command and General Staff College.

\section{REFERENCES}

1. Barber, M., and Njus, D., 2007. Clicker Evolution: Seeking Intelligent Design, CBE-Life Sciences Education, 6 (1), 1-20.

2. Carnaghan, C., Webb, A., 2007. Investigating the Effects of Group Response systems on Student Satisfaction, Learning, and Engagement in Accounting Education, Issues in Accounting Education, 22 (3), 391-409.

3. Cohen, J. S., 2005. Personal Response Systems Changing College Classrooms, Chicago Tribune, July 14, 2005.

4. Cunningham, B.M., 2008. Using Action Research to Improve Learning and the Classroom Learning Environment, Issues in Accounting Education, 23(1), 1-30.

5. eInstruction, 2009. Higher Education Solutions, Retrieved October 23, 2009, from http://www.einstruction.com/classroom solutions/higher education.html

6. Francisco, W., Noland, T.G., and Sinclair, D. 2006. Are Remote Access Devices the Key to Active Learning? Presented at the American Accounting Association Annual Meeting, Washington, D.C., August 6-9.

7. Hatch, Jay, Jensen, M., Moore, R., July/August 2005; "Manna from Heaven or 'Clickers' from Hell, Journal of College Science Teaching, 34 (7), 36 to 39.

8. Heizer, J., and Render, B. (2006): “Operations Management at the Barber Shop,” p277; Operations Management. ${ }^{\text {th }}$ Edition; Pearson Prentice Hall.

9. Herreid, C.F., 2006. Clicker' Cases: Introducing Case Study Teaching Into Large Classrooms, Journal of College Science Teaching, 36 (2), 43 to 47. 
10. Northwestern University, 2006. Personal Response System Boosts Class Participation Retrieved November 8, 2005 from http://www.northwestern.edu/newscenter/stories/2005/11/clickers.html 11.

11. Rutner, Stephen, 2004. Exploratory Study Into the Use of Hyper-Interactive Teaching Technology in the Logistics and Transportation Classroom, Journal of Transportation Management, 15 (1), 42-54.

12. Stowell, J.R., Nelson, J.M., 2007. Benefits of Electronic Audience Response Systems on Student Participation, Learning, and Emotion, Teaching of Psychology, 34 (4), 253-258.

\section{NOTES}

